Article

\title{
Environmental Permitting and Compliance Cost Reduction Strategies for the MHK Industry: Lessons Learned from Other Industries
}

\author{
Sharon Kramer ${ }^{1, *}$, Craig Jones ${ }^{2, *}$, Geoffrey Klise ${ }^{3}$, Jesse Roberts ${ }^{3}$, Anna West ${ }^{4}$ and Zach Barr ${ }^{4}$ \\ 1 H. T. Harvey \& Associates, Arcata, CA 95521, USA \\ 2 Integral Consulting Inc., Santa Cruz, CA 95060, USA \\ 3 Sandia National Laboratories, Albuquerque, NM 87123, USA; gklise@sandia.gov (G.K.); \\ jdrober@sandia.gov (J.R.) \\ 4 Kearns \& West, Inc., San Francisco, CA 94104, USA; awest@kearnswest.com (A.W.); \\ zbarr@kearnswest.com (Z.B.) \\ * Correspondence: skramer@harveyecology.com (S.K.); cjones@integral-corp.com (C.J.)
}

Received: 19 June 2020; Accepted: 21 July 2020; Published: 24 July 2020

\begin{abstract}
The marine and hydrokinetic (MHK) industry plays a vital role in the U.S. clean energy strategy by providing a renewable, domestic energy source that may offset the need for traditional energy sources. The first MHK deployments in the U.S. have incurred very high permitting costs and long timelines for deploying projects, which increases project risk and discourages investment. A key challenge to advancing an economically competitive U.S. MHK industry is reducing the time and cost required for environmental permitting and compliance with government regulations. Other industries such as offshore oil and gas, offshore wind energy, subsea power and data cables, onshore wind energy, and solar energy facilities have all developed more robust permitting and compliance pathways that provide lessons for the MHK industry in the U.S. and may help inform the global consenting process. Based on in-depth review and research into each of the other industries, we describe the environmental permitting pathways, the main environmental concerns and types of monitoring typically associated with them, and factors that appear to have eased environmental permitting and compliance issues.
\end{abstract}

Keywords: marine and hydrokinetic energy; environmental permitting; environmental compliance; other industries

\section{Introduction}

Marine and hydrokinetic (MHK) technologies convert the energy of waves, tides, rivers and ocean currents into electricity; this emerging industry can play a vital role in the U.S. clean energy strategy by providing a renewable, domestic energy source. The MHK industry can help offset the need for traditional energy sources, such as coal and gas, which contribute to detrimental long-term impacts on the global climate and support foreign dependencies that put the U.S. at risk. The first MHK project deployments in the U.S. have incurred very high permitting costs, which increase project risk and discourage investment for the nascent industry [1]. A key challenge to advancing an economically competitive U.S. and global MHK industry is reducing the time and costs required to achieve environmental permitting and compliance with federal, state, and local regulations.

Quantifying environmental permitting and compliance costs and formulating cost reduction pathways for MHK development are especially difficult for several reasons: (1) environmental baseline data are limited; (2) environmental effects may be specific to a technology type or site and not comparable among different technologies and sites; (3) potential environmental impacts are not well understood, so a conservative and 
precautionary approach to regulating the technologies often prevails; and (4) environmental compliance monitoring costs in marine environments are typically high [1]. These challenges are compounded by the lack of operational experience in MHK technology—there are few MHK projects in the water.

Similar industries that have existed longer than the MHK industry have identified strategies to increase efficiencies in environmental permitting, evaluate and mitigate impacts, and reduce permitting costs [2]. These industries include marine developments such as offshore oil and gas, offshore wind energy, and subsea power and data cables, as well as terrestrial renewable energy developments such as wind energy and solar energy facilities. Some of the "lessons learned" from these industries, relating to increased efficiency and improved environmental permitting pathways, have successfully reduced costs. This review provides perspectives on the applicability of lessons learned from environmental permitting for other U.S. industries to the emerging U.S. MHK industry. These lessons learned may also help inform the global environmental consenting process where there are similar permitting requirements. The evaluations are based on the environmental permitting pathways, present trends in the Levelized Cost of Energy (LCOE), overall permitting costs, and factors that have eased environmental permitting and compliance level of effort in other industries.

\section{Methodology}

We evaluated the available information on the costs of permitting, constructing, and operating offshore oil and gas, offshore wind energy, subsea power and data cables, and terrestrial wind and solar energy industries, and how these costs have evolved over time. For energy industries, we reviewed available information on the LCOE, which is defined as the net present value of the unit cost of electricity over the lifetime of a generating asset, often reported per kilowatt-hour $(\mathrm{kWh})$ or megawatt-hour (MWh). The portion of the LCOE (e.g., construction and operation costs) attributable to environmental permitting was generally not available or explicitly calculated, so we determined the historical and projected future costs for the energy industries. For each industry, we also described the environmental permitting pathways, the primary potential environmental effects, the types of compliance monitoring typically associated with those effects, and factors that appear to have eased environmental permitting and compliance issues. Finally, for each industry, we identified the factors that have contributed to increasing efficiencies and facilitating environmental permitting, such as permitting and regulatory solutions; partnerships and collaborative research; and guidance, protocols, and siting tools. We prioritized information obtained from peer-reviewed literature when available; however, in many cases, information was only available in gray literature.

To augment the available information, we contacted a small number of industry representatives or their environmental consultants, and regulatory agency personnel to capture their experiences and perspectives on permitting and compliance costs, and strategies to reduce these costs. Project permitting cost information is typically proprietary, so we obtained proprietary, project-specific information on a voluntary and anonymous basis by providing participants with a list of questions and conducting follow-up interviews. The questions were focused on gleaning information on participants' years of experience, their industry projects, the environmental concerns associated with the industry, and the permitting pathways including permitting challenges, efficiencies, and timelines, and permitting cost as a proportion of total project cost.

\section{Marine Industries}

Offshore oil and gas development, subsea cables, and offshore wind energy development are good comparison cases for MHK development because they share similarities in their environmental permitting pathways and environmental effects. These marine industries in the U.S. are subject to oversight by regulatory agencies and to myriad federal permitting requirements, as well as state and local regulations. The types of potential environmental effects associated with these industries include the loss and/or alteration of benthic habitat, degradation of water quality, increases in ambient noise and light levels, collisions with 
marine wildlife, electromagnetic field (EMF) emissions from subsea power or data cables, and changes in marine wildlife behavior (e.g., avoidance) that may result in deleterious effects on populations.

\subsection{Environmental Permitting Pathways}

Most marine industries, including MHK developments, have a "federal nexus" (e.g., where a federal agency is undertaking, funding, permitting, or authorizing actions) and are subject to National Environmental Policy Act (NEPA) review to assess the consequences of the project for the natural and human environment, including wildlife and cultural resources. The construction, maintenance, operation, and decommissioning of facilities and associated infrastructure is all considered part of the "action" and subject to the NEPA [3]. Many additional regulations and permitting requirements also may apply (Table 1). Federal regulations that often have the most significant and costly environmental permitting and compliance requirements include the Endangered Species Act (ESA), the Migratory Bird Treaty Act (MBTA), the Marine Mammal Protection Act (MMPA), the Coastal Zone Management Act (CZMA), and the Magnuson-Stevens Fishery Conservation and Management Act (Essential Fish Habitat [EFH]).

Table 1. Regulatory Agencies, Federal Regulations, and Types of Environmental Permitting Requirements That May Apply to Marine Industries in the U.S.

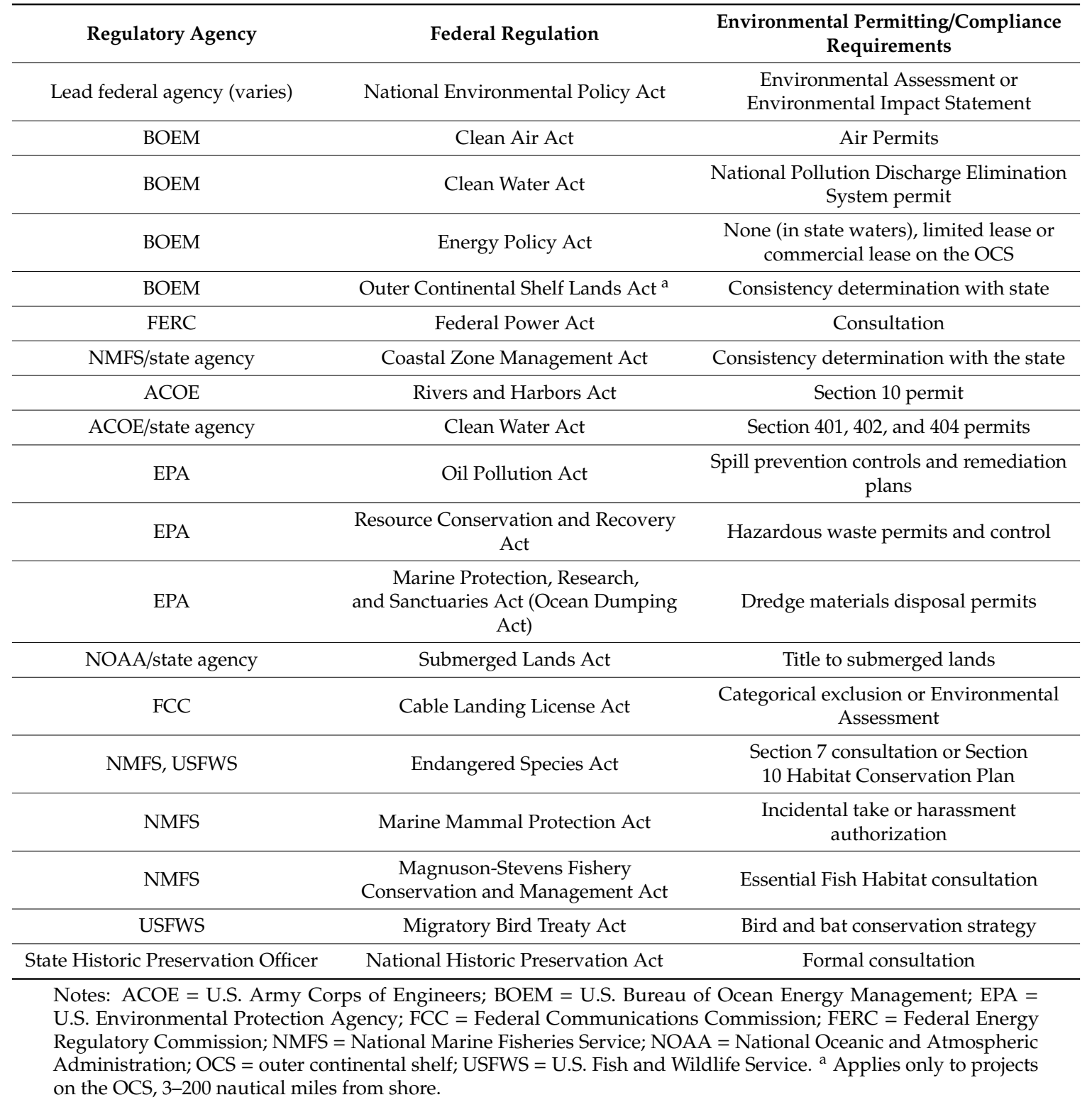


The permitting pathway for marine industries varies depending on whether the project will be located entirely within state waters ( 3 nautical miles from shore) or across state waters to the outer continental shelf (OCS) (3-200 nautical miles from shore). Both state and federal regulations apply to projects in state waters, whereas mainly federal regulations apply to projects on the OCS (although some state regulations may also apply on the OCS). In state waters and at the point of onshore activities (e.g., cable landings), state and local regulations apply, and these differ by site.

\subsection{Offshore Oil and Gas}

\subsubsection{Changes in Levelized Cost of Energy over Time}

The LCOE related to offshore oil and gas ranged from $\$ 0.05 / \mathrm{kWh}$ to $\$ 0.28 / \mathrm{kWh}$ in 2016 [4]. Fossil fuels, including oil and gas, provide the lowest cost of energy in the U.S. and for most of the world. The low cost is primarily due to the ease of extraction. Because the offshore oil and gas industry began evolving in the U.S. in the late 19th century during a period with no environmental regulation, it is difficult to draw parallels for the industry between the change in energy costs and the evolution of environmental permitting. The low LCOE currently enables a continuing large scale of offshore oil and gas development. Generally, the cost of environmental permitting is low relative to overall development expenditure, with an estimated $5-7 \%{ }^{1}$ of total development costs attributed to environmental permitting.

Although environmental permitting costs for oil and gas development represent a relatively low percentage of the LCOE, these average costs do not adequately capture the opportunity costs of development: obstacles and a lengthy permitting process can sometimes cause loss of investment or project cancellation. ${ }^{1}$ This generally occurs in locations lacking a history of oil and gas development, such as the Arctic, and occurs less often in locations that have a long history of development, such as the Gulf of Mexico. Thus, permitting duration and/or costs are influenced by location and deviate from initial project estimates at least one-third of the time. ${ }^{1}$ In the U.S., oil and gas permitting costs generally are highest in Alaska and lowest in the Gulf of Mexico region. ${ }^{1}$

\subsubsection{Potential Environmental Effects and Types of Monitoring}

Potential environmental effects associated with offshore oil and gas development include discharges or spills of toxic substances and related effects on wildlife and water quality, noise and disturbance to marine life during construction and operations, damage to marine habitats caused by the construction and presence of infrastructure, and attraction of some phototactic seabird species to lighting on oil platforms. Fish, sea turtles, and marine mammals maybe also be attracted to or avoid the platforms, which may be deleterious. The activities and potential effects generally considered for projects in this industry are shown in Table 2.

1 Interview with oil and gas industry consultant, 20 November 2017. All interviews were conducted in confidentiality, and the names of interviewees are withheld by mutual agreement.

1 Interview with oil and gas industry consultant, 20 November 2017. All interviews were conducted in confidentiality, and the names of interviewees are withheld by mutual agreement.

1 Interview with oil and gas industry consultant, 20 November 2017. All interviews were conducted in confidentiality, and the names of interviewees are withheld by mutual agreement.

1 Interview with oil and gas industry consultant, 20 November 2017. All interviews were conducted in confidentiality, and the names of interviewees are withheld by mutual agreement. 
Table 2. Offshore Oil and Gas Industry Activities and Associated Stressors.

\begin{tabular}{cc}
\hline Activity & Potential Stressors \\
\hline Site surveying and characterization & Physical disturbance, noise \\
\hline Exploration drilling & Physical disturbance; noise; and air, water, and seafloor discharges \\
\hline Production & Physical disturbance; noise; air, water, and seafloor discharges; and \\
lighting
\end{tabular}

\subsubsection{Factors Contributing to Easing Environmental Permitting}

Several factors have contributed to increasing efficiencies and facilitating environmental permitting for offshore oil and gas development. These include permitting and regulatory solutions, as well as partnerships formed among industry, agencies, and scientists, which result in collaborative research. Specific guidance, protocols, and siting tools were not identified because the BOEM identifies sites for oil and gas development through its National OCS Oil and Gas Leasing Program [5].

\section{Permitting and Regulatory Solutions}

The BOEM plays a major role in facilitating environmental permitting for offshore oil and gas development. The BOEM prepared the 2019-2024 National OCS Oil and Gas Leasing Draft Proposed Program (DPP) for 25 of 26 planning areas of the OCS [5,6]. The DPP is an effort to gather information for future decision-making and lead to a draft proposed program, which is then analyzed in a Draft Programmatic Environmental Impact Statement (Draft PEIS).

The PEIS will analyze potential lease areas and lead to a proposed final program and Final PEIS. Once the final program is approved, as part of individual lease sales, the BOEM prepares Information to Lessee (ITL) documents, providing information to lessees about particular environmental and sociocultural concerns, regulatory and stakeholder concerns, required mitigation, and requirements of other federal and state agencies. Because the BOEM conducts the environmental analyses and provides baseline resource, regulatory, and stakeholder information, the burden on industry is substantially reduced, and the permitting process eased. The role of the BOEM in conducting analyses and administering regulations minimizes the potential environmental impacts from oil and gas activities on the OCS and reduces environmental permitting costs to developers.

\section{Partnerships and Collaborative Research}

The partnerships and collaborative research in the offshore oil and gas industry involve international, national, and regional entities that serve multiple functions in the industry. Examples of such entities include the Joint Industry Programme; National Academies of Sciences, Engineering, and Medicine; National Petroleum Council; and Western States Petroleum Association. The partnerships function as interfaces among the U.S. offshore oil and gas industry, federal government, industry professionals in other countries, and the public. They convene study teams/panels of recognized professionals and varied skills/perspectives to evaluate environmental effects, conduct research, and develop standards for the offshore oil and gas industry.

\subsubsection{MHK Industry Application}

Permitting pathways in the offshore oil and gas industry have been made more efficient and effective through the BOEM's contributions and collaboration among regulatory agencies, industry professionals, and subject matter experts. The BOEM reduces the permitting costs and time frames for the offshore oil and gas industry by completing environmental analyses, providing environmental baseline information, administering regulations, and sharing stakeholder information. The partnerships provide a productive interface among regulatory agency personnel, industry professionals, and technical 
experts to reach a shared level of understanding about industry issues, some of which are quite controversial, through study panels, collaborative research, and joint publications. The MHK industry can apply the lessons from the offshore oil and gas industry by engaging the BOEM to contribute in a manner comparable to its role in the offshore oil and gas industry, and facilitate collaboration among regulatory agencies, industry professionals, and subject matter experts to reach consensus on environmental and permitting issues.

\subsection{Subsea Cables}

Subsea cables provide communications or power from land to land across water bodies. Subsea cables have been around for more than 100 years, and some are thousands of kilometers $(\mathrm{km})$ in length. The first transatlantic telegraph cable was laid in 1866 and stretched $4000 \mathrm{~km}$ from Ireland to Newfoundland, Canada.

Subsea cables include power cables designed to transmit electric current (direct current [DC] or alternating current $[\mathrm{AC}]$ ), data/telecommunications cables, and cables that transmit both electric current and data/telecommunications. Both power and data cables are used in offshore wind energy, MHK, and offshore oil and gas developments to transmit power and data. The environmental effects of cable installation and operation are considered in the permitting of these developments.

\subsubsection{Changes in Development Costs over Time}

Costs associated with subsea cables include the cost of the cables; offshore, landfall, and onshore installation costs; and costs of repair or removal (costs were adjusted for inflation with 2014 as the base year [6]). In Europe, current installation costs vary widely, from 0.25 to 1.4 million Euros $/ \mathrm{km}$ ( $\$ 0.3$ to $\$ 1.7$ million $/ \mathrm{km}$ ) $[4,7]$. The exact portion of costs attributed to environmental permitting is unknown, but is less than 10\% [6]. Figure 1 shows the overall cost breakdown of subsea cables; the category "others" (10\% of costs) includes project management, regulatory requirements and consents, and studies and surveys [6].

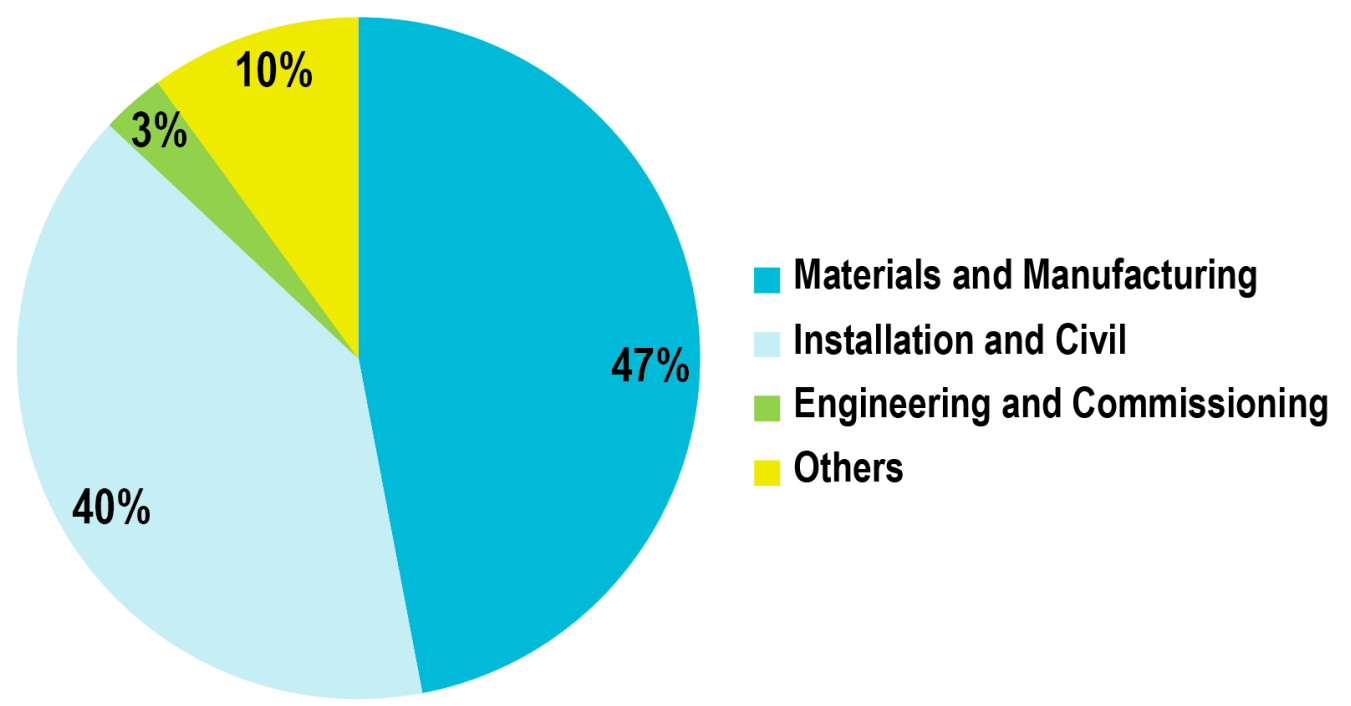

Figure 1. Cost breakdown for subsea cables. Adapted from [6].

\subsubsection{Potential Environmental Effects and Types of Monitoring}

The potential environmental effects and types of monitoring required for the marine and terrestrial components of subsea cable projects may differ substantially. The potential effects on the marine environment that are associated with properly sited and installed subsea cables generally are considered to be minor [8], and include short-term and localized disturbance of the seabed and marine biota during cable installation, repair, or removal; potential sound disturbance and vessel collisions with 
marine mammals during installation; and the effects on electrosensitive species from EMFs emitted by cables [9]. Whale entanglement with surface-laid cables that form coils or loops was a problem until the 1950s, when advances in cable design, surveying, and installation techniques eliminated this issue [10]. Types of monitoring required in the marine environment may include preinstallation mapping to locate a suitable installation pathway and avoid impacts, use of observers on the vessel during installation to prevent collisions with marine mammals, and postinstallation monitoring and evaluation of maintenance/repairs and impacts. Monitoring for sensitive biological resources in terrestrial environments typically involves retaining a qualified biological monitor (e.g., approved by applicable regulatory agency) during project construction or project activities such as maintenance during the bird breeding season that may result in the disturbance of nesting birds.

\subsubsection{Factors Contributing to Easing Environmental Permitting}

Several factors have contributed to increasing efficiencies and facilitating environmental permitting for subsea cables. These include permitting and regulatory solutions; partnerships formed among industry, agencies, and scientists and the collaborative research conducted by these partnerships; and the creation of guidance, protocols, and siting tools.

\section{Permitting and Regulatory Solutions}

Programmatic NEPA reviews have been conducted to facilitate and improve environmental permitting of subsea cables and reduce environmental permitting costs. For example, the Final Programmatic Environmental Assessment for National Science Foundation-Funded Ocean Observatories Initiative (OOI) was prepared to analyze the potential impacts of the installation and operation of the OOI, a network of ocean sensors with subsea cables that connect to shore and provide power and internet connectivity. One array is located on the U.S. West Coast and the other is on the U.S. East Coast (1238 km and $100 \mathrm{~km}$ of cable, respectively) [11]. Site-specific, tiered EAs were then used to address individual actions as needed. This strategy provided for early identification and analysis of potential impacts and methods to mitigate them, while allowing for introduction of more detailed technical and time- and location-specific information when it became available. With the initial analyses already completed in the programmatic EA, less time was required to complete the site-specific tiered EAs and likely resulted in cost savings for environmental permitting.

The environmental impacts analyzed for subsea cable projects likely would be similar to those associated with the cable array portion of a MHK project; thus, an EA developed for subsea cables could be useful in assessing a proposed MHK project in the same area.

\section{Partnerships and Collaborative Research}

The partnerships and collaborative research in the subsea cable industry involve international, national, and research entities that are focused on sharing information relevant to developers and funding research on the effects of EMFs emitted by subsea cables on the marine environment. The North American Submarine Cable Association (NASCA) provides and exchanges information on issues related to cable installation, including environmental permitting. This nonprofit association represents companies that own, install, or maintain telecommunications cables in the waters of North America.

The BOEM has funded, and continues to fund, research projects to evaluate the effects on marine species from EMFs emitted by ocean power cables. Although electrosensitive species likely detect EMFs from power cables, the emissions are limited spatially to a few meters, reducing these species' potential exposure and the risk of impacts, especially when cables are shielded and buried [12-15]. Most research to date has concluded that there is likely little biological response to EMFs emitted by power cables [16,17], based on experimental approaches, mesocosms, large-scale field studies, behavioral studies, and measurements of EMFs from cables of various sizes [13,14,18,19]. Laboratory studies have been used to detect "dose-response" relationships, for example, how species behavior changes with exposure to EMFs [20]. Field surveys are also used to determine whether species behaviors or 
distributions are affected by EMFs at actual cables $[13,14,19]$. Although experimental research and field surveys have been limited and recent, work to date indicates there is no clear level of EMF identified to cause impacts on biota from anthropogenic sources of EMFs such as subsea cables. These findings should be clearly communicated to contribute to efficiencies in the permitting and licensing process, including environmental compliance monitoring, by reducing the need for additional studies or mitigation measures.

\section{Guidance, Protocols, and Siting Tools}

The Oslo/Paris Convention for the Protection of the Marine Environment of the Northeast Atlantic (managed by the OSPAR Commission) developed nonbinding Guidelines on Best Environmental Practice (BEP) in Cable Laying and Operating [21]. Additionally, the National Oceanic and Atmospheric Administration (NOAA) Office of Marine Sanctuaries Final Policy and Permit Guidance for Submarine Cable Projects provides applicants with guidance for installing and maintaining submarine cables in National Marine Sanctuaries [22]. Lastly, the Naval Seafloor Cable Protection Office manages a worldwide geographic information system (GIS) database of commercial and government submarine cable systems and supporting datasets. These are used for planning, siting, and surveying for cable sites [23].

\subsubsection{MHK Industry Application}

Permitting pathways in the subsea cable industry have been made more efficient and effective through permitting and regulatory solutions; partnerships among industry professionals, regulatory agencies, and subject matter experts and their collaborative research; and the development of guidance, protocols, and siting tools. Conducting programmatic NEPA reviews (i.e., EAs) enabled the early identification and analysis of potential environmental effects and mitigation, which resulted in less time (and costs) to prepare site-specific, tiered EAs. The NASCA represents a partnership between telecommunications-associated companies that provides and exchanges information on issues related to cable installation, including environmental permitting. The BOEM partners with researchers to provide funding to evaluate the effects of EMFs emitted by subsea cables on marine species. Guidance and tools (e.g., GIS databases) for planning, siting, installing, and maintaining subsea cables, as well as recommended best environmental practices, are available to the subsea cable industry. The MHK industry can apply lessons from the subsea cable industry by conducting programmatic NEPA reviews to enable tiering of site-specific EAs, forming partnerships (e.g., among MHK developers) to exchange data and information on environmental effects and permitting, and obtaining BOEM funding for research on the effects of MHK project cable EMFs on marine organisms, The MHK industry could also use EAs developed for subsea cables in the same areas as proposed MHK projects to assess similar environmental effects (e.g., from cable arrays for an MHK project), and utilizing applicable guidance and tools from the subsea cable industry.

\subsection{Offshore Wind Energy}

Offshore wind energy development is still a fledgling industry in the U.S. However, the worldwide capacity of offshore wind energy has increased to over 7 gigawatts (GW) in recent years and continues to increase, with approximately $90 \%$ of the global capacity in northern Europe [24]. Existing developments are typically located at depths of less than 50 meters and constructed with fixed-bottom foundations (e.g., wind turbines supported by a foundation such as monopole, jacket, or gravity base that is fixed to the seabed), which precludes the use of faster winds farther offshore. Wind turbines supported by a floating platform moored to the seafloor, such as spar buoy, semisubmersible or tension-leg platform, are being developed to allow for projects in much deeper waters farther offshore from land. Only one offshore wind project has been constructed in U.S. waters-the Block Island Wind Farm off Rhode Island, which is discussed below-but more than 20 projects totaling nearly 25,000 MW are in the pipeline as of 2016 [25]. 


\subsubsection{Changes in Levelized Cost of Energy over Time}

There was an initial reduction in the LCOE for the first fixed-bottom offshore wind installations in the 1990s, steeply increasing costs in the 2000s, and some cost reductions more recently [26]. As of 2014, the baseline LCOE for fixed-bottom offshore wind projects was estimated at \$169-171 per MWh based on existing projects in Europe. Compared to the 2014 baseline, the LCOE is projected to decline by $10 \%$ in 2020 , by $30 \%$ in 2030 , and by $41 \%$ in 2050 , driven in part by capacity factor (Figure 2) [26]. Owing to a lack of deployments of floating offshore wind projects, the baseline LCOE for these installations could not be estimated, but is projected to be $6 \%$ above the 2014 LCOE of fixed-bottom wind energy installations in 2020, 25\% below it in 2030, and 38\% below it in 2050 (Figure 2) [26]. The portion of costs attributed to environmental permitting is unknown; however, the costliest aspect generally consists of the baseline studies conducted by contractors.

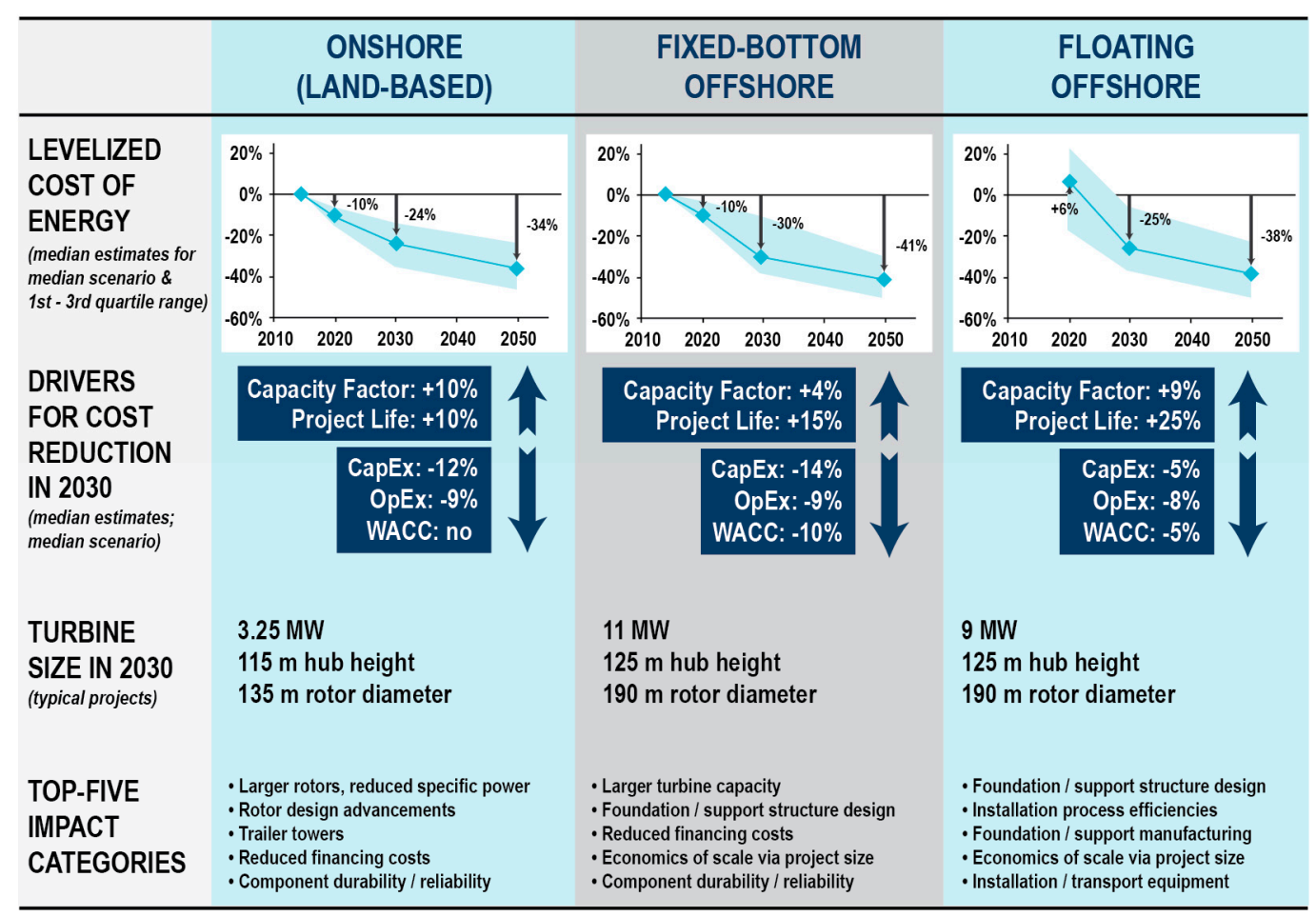

Figure 2. Summary of projected LCOE reductions for onshore wind, fixed-bottom offshore wind, and floating offshore wind installations for the period 2020-2050. Adapted from [26]. CapEx = Capital Expenditures, OpEx = Operational Expenditures, and WACC $=$ Weighted Average Cost of Capital.

\subsubsection{Potential Environmental Effects and Types of Monitoring}

Potential environmental effects related to offshore wind energy development include noise and other disturbance of marine species during installation and operation; bird and bat collisions with turbines; attraction of phototactic seabirds to lighting on the turbines; effects on fish and invertebrate species that are sensitive to EMFs emitted by power cables; effects on marine mammals, sea turtles, and fish from sound emitted underwater during project installation and operation; entanglement of marine mammals with the interarray cables or with lost fishing gear that becomes tangled on the mooring lines of floating wind turbines; and indirect effects on fish and benthic organisms that are attracted to floating platforms, moorings and anchors $[27,28]$. These interactions typically require evaluations of best available science, baseline and effects monitoring [29], and consultations or permits as described previously, that are conducted or obtained at a cost to the developer. 


\subsubsection{Factors Contributing to Easing Environmental Permitting}

Several factors have contributed to improving efficiencies and facilitating environmental permitting for offshore wind energy. These include permitting and regulatory solutions; partnerships formed among industry, agencies, and scientists and the collaborative research conducted by these partnerships; and the creation of guidance, protocols, and siting tools.

\section{Permitting and Regulatory Solutions}

As described for offshore oil and gas development, the BOEM is authorized to issue leases for renewable energy development on the OCS, and serves as the lead federal agency conducting environmental review for these leases. In 2007, the Minerals Management Service (now the BOEM) prepared the Programmatic EIS for Alternative Energy Development and Production and Alternate Use of Facilities on the OCS [3]. This document evaluates potential impacts from offshore wind, wave, and ocean current energy capture technologies and identifies appropriate mitigation measures and best management practices (BMPs), but does not evaluate site-specific issues; such effects must be evaluated at the project level.

Recently, the U.S. Department of Energy (DOE) and Department of the Interior (DOI) released the National Offshore Wind Strategy, an action plan for the DOE and the DOI to facilitate the development of the offshore wind industry in the U.S. [30]. For the mid-Atlantic states-Delaware, Maryland, New Jersey, New York, and Virginia-the Guide to State Management of Offshore Wind Energy in the Mid-Atlantic Region provides a framework for managing environmental permitting and compliance for offshore wind energy development in state waters [31]. This framework included the BOEM's "Smart from the Start" Initiative from late 2010 that had a goal to streamline offshore wind projects in federal waters in the Atlantic Ocean by expediting leasing, increasing regional coordination, and identifying priority wind energy areas most suitable for development [31].

\section{Partnerships and Collaborative Research}

The partnerships and collaborative research in the offshore wind energy industry involve federal and state agencies, national laboratories, regional planning entities, federal/state task forces, academic partnerships, and nonprofit organizations. Examples of entities involved in collaborative research include the BOEM, the DOE's Wind Energy Technologies Office (WETO), the DOE's National Renewable Energy Laboratory (NREL), Sandia National Laboratories, the Pacific Northwest National Laboratory (PNNL), the American Wind Wildlife Institute (AWWI), the Pacific Marine Energy Center, the Northeast Ocean Planning Region, and the Mid-Atlantic Regional Council on the Ocean. The partnerships provide multiple services, including funding and conducting collaborative research to reduce the environmental effects and costs of offshore wind energy development; creating online libraries of industry documents; providing GIS portals and geospatial datasets with mapping tools; and exchanging data and information to facilitate responsible development of offshore wind energy.

The BOEM, the WETO, the NREL, Sandia National Laboratories, and the PNNL often collaborate with industry groups, academia, and agencies to fund and cost-share wind energy research and development. Collaborative research has spurred technological advances that are expected to reduce environmental monitoring costs, improve data collection, and potentially reduce impacts on marine wildlife. The technological developments that have been tested and continue to be refined include high-resolution digital aerial imagery, thermal imagery, and sensors (optic, bio-acoustic, ultrasound, and vibration) [32-34]. The PNNL maintains Tethys [35], an online, searchable platform with published and unpublished (but publicly available) documents on the environmental effects of marine renewable energy (MRE) projects such as offshore wind and MHK developments. Federal-state task forces have been created between the BOEM and Oregon, California, and almost all U.S. East Coast states to facilitate renewable marine energy development on the OCS [36]. The BOEM also develops, maintains, and provides GIS data related to planning, assessment, and environmental review of MRE projects. Some states, like California, have developed their own GIS data portals for offshore wind energy development [37]. 


\section{Guidance, Protocols, and Siting Tools}

Protocols for monitoring and studies of offshore renewable energy include Developing Environmental Protocols and Modeling Tools to Support Ocean Renewable Energy and Stewardship [38] and West Coast Environmental Protocols Framework: Baseline and Monitoring Studies [29]. Guidance on power cable installation for wind energy developers can be found in the Offshore Wind Submarine Cable Spacing Guidance [39] and Offshore Electrical Cable Burial for Wind Farms: State of the Art, Standards and Guidance $\mathcal{E}$ Acceptable Burial Depths, Separation Distances and Sand Wave Effect [40]. The Evaluation of Lighting Schemes for Offshore Wind Facilities and Impacts to Local Environments contains a set of best practices for lighting at offshore wind facilities [41].

\subsubsection{MHK Industry Application}

Permitting pathways in the offshore wind energy industry have been made more efficient and effective through permitting and regulatory solutions; partnerships formed among industry, agencies, and scientists and the collaborative research conducted by these partnerships; and the development of guidance and tools. The programmatic EIS prepared by the Minerals Management Service (now the BOEM) provides program-level analyses of potential environmental effects from offshore wind, wave, and ocean current energy capture technologies and identifies appropriate mitigation measures and BMPs. Government agencies (e.g., the BOEM and the WETO) and national laboratories (e.g., the NREL and the PNNL) support research to reduce the risks to marine wildlife from offshore wind energy development, often collaborating with industry groups, academia, and agencies to fund and cost-share research and development to improve performance, lower costs, and reduce market barriers. This collaborative research has driven technological advances that are expected to reduce environmental monitoring costs, improve data collection, and potentially reduce impacts on marine wildlife. The DOE is partnering with wind developers and federal agencies between 2020 and 2025 to evaluate the environmental impacts of first-generation offshore wind projects in the U.S., test monitoring and mitigation technologies, and develop predictive models of potential impacts. The National Offshore Wind Strategy and Guide to State Management of Offshore Wind Energy in the Mid-Atlantic Region provide guidance for offshore wind energy development, including permitting and compliance processes.

The MHK industry can apply lessons from the offshore wind energy industry by conducting a comprehensive review of the studies, guidance, tools, and protocols that have been developed for the offshore wind energy industry to identify applicable resources and avoid duplicating efforts. Identifying collaborative research opportunities with funding from government agencies or national laboratories; forming partnerships among regulatory agencies, industry professionals, and subject matter experts to address environmental effects and permitting; and developing publicly available tools to inform MHK projects would also benefit the MHK industry. The MHK industry could also benefit from the offshore wind energy industry by identifying opportunities for teaming between the two industries in areas of overlap (e.g., project siting and marine environmental effect analyses).

\section{Terrestrial Renewable Energy Industries}

Terrestrial wind and solar energy are relevant to MHK development because they share some similarities in their environmental permitting pathways, but have been around for longer and thus have developed permitting strategies that can be applied to MHK projects.

\subsection{Environmental Permitting Pathways}

The environmental permitting pathway for a terrestrial renewable energy project varies by whether the project is proposed for public lands (e.g., those managed by the U.S. Bureau of Land Management [BLM] or the U.S. Forest Service [USFS]), private lands with a "federal nexus" (e.g., where a federal agency is undertaking, funding, permitting, or authorizing actions), or private lands with no federal nexus. Projects with a federal nexus are subject to NEPA review to assess the consequences of the project 
for the natural and human environment, including plants, wildlife, and cultural resources. There are also a number of other regulations and permitting requirements that may apply (e.g., the Clean Water Act and the ESA). Actions that are subject to permitting and compliance include the installation, maintenance, repair, operation, and removal of facilities and associated infrastructure.

The ESA, the MBTA, and the Bald and Golden Eagle Protection Act (BGEPA) often present significant and costly environmental permitting and compliance requirements. A Section 7 ESA consultation with the U.S. Fish and Wildlife Service (USFWS) is required if the project may affect federally listed species and is sited either on public lands or on private lands with a federal nexus. If the project is on private lands lacking a federal nexus, a Habitat Conservation Plan (HCP) may be required to obtain authorization for "take" of federally listed species in the course of otherwise lawful activities ("take," as defined by the ESA, means to harass, harm, pursue, hunt, shoot, wound, kill, trap, capture, or collect, or to attempt to engage in any such conduct). There are also state and local permit requirements that vary by location.

\subsection{Wind Energy}

Terrestrial wind energy development in the U.S. began in the 1970s after the federal government started offering tax incentives for renewable energy, making it a profitable endeavor for landowners. Wind turbine production and technology has changed dramatically over the last 30-40 years; it began with small towers and turbines fabricated in machine shops, and eventually moved to industrial-scale production of larger, higher-capacity turbines [42] (Figure 3). There was limited understanding and oversight of potential environmental impacts until one of the earliest developments, the Altamont Pass Wind Resource Area in California, was found to have large numbers of golden eagle (Aquila chrysaetos) and other raptor fatalities caused by collisions with turbines [43]. This led to increasing environmental review and oversight, and spurred changes in turbine design, operational management, and research to reduce impacts.

\section{EVOLUTION OF U.S. COMMERCIAL WIND TECHNOLOGY}

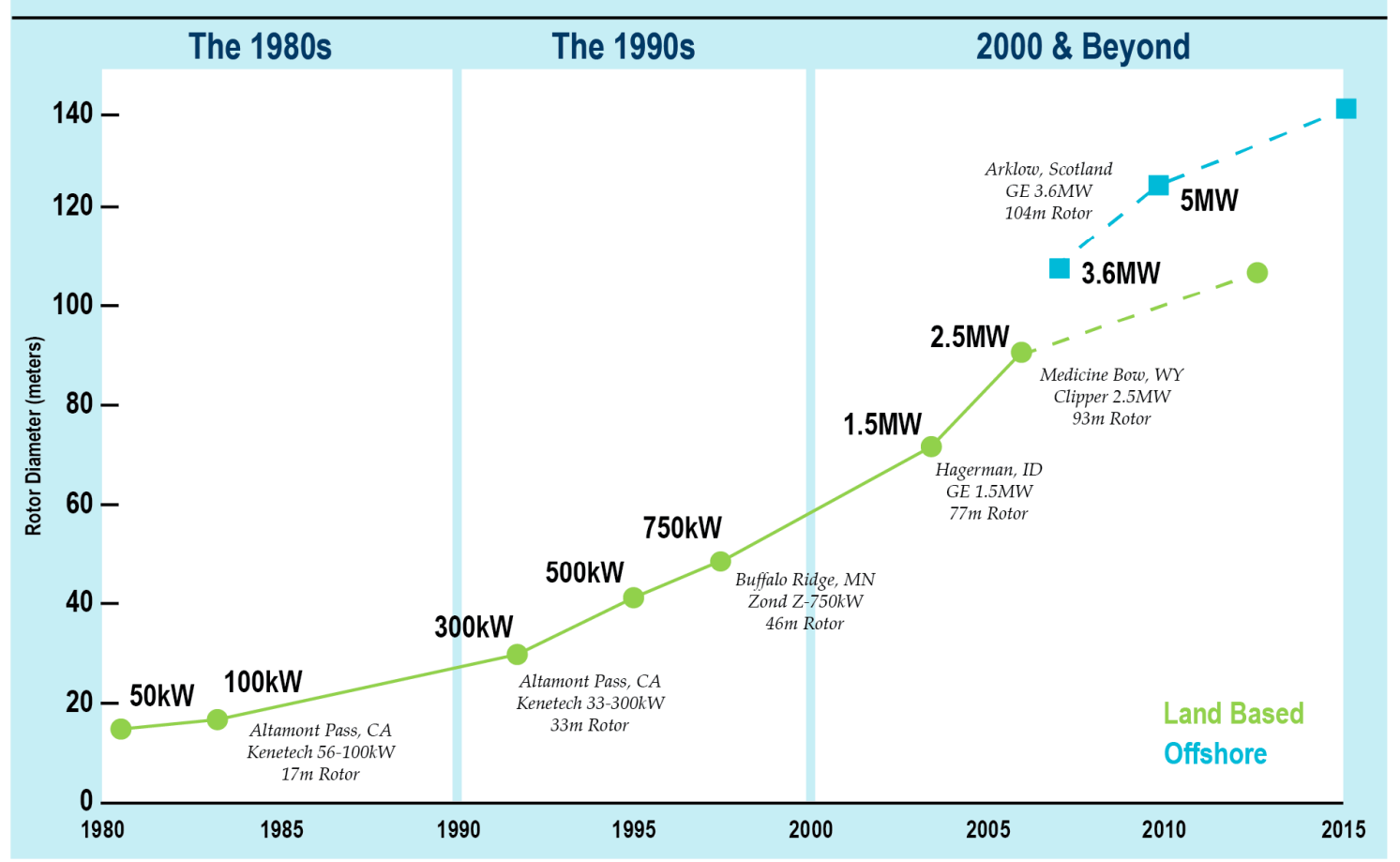

Figure 3. The evolution of U.S. commercial wind technology. Note that rotor diameter increased project capacity over time, with largest rotor diameters being proposed for offshore wind projects. Adapted from [42]. 


\subsubsection{Changes in Levelized Cost of Energy over Time}

In the U.S. and Europe, the LCOE for wind decreased dramatically from approximately \$150/MWh in the 1980s to approximately $\$ 50 / \mathrm{MWh}$ in the early 2000s, owing to technology developments and refinements [42,44]. However, the LCOE saw an uptick in the period 2004-2009, reaching approximately $\$ 75 / \mathrm{MWh}$, a rise attributed to the increasing cost of materials, labor, and turbine upscaling [44]. The LCOE declined by 66\% in the period 2009-2016 [4] (Figure 4), thanks to performance improvements that outweighed the higher capital costs [44], and compared to 2014 costs, it is projected to decline by $10 \%$ in 2020 , by $24 \%$ in 2030, and by $35 \%$ in 2050 [26]. The proportion of the LCOE attributed to environmental permitting was not reported in these studies.

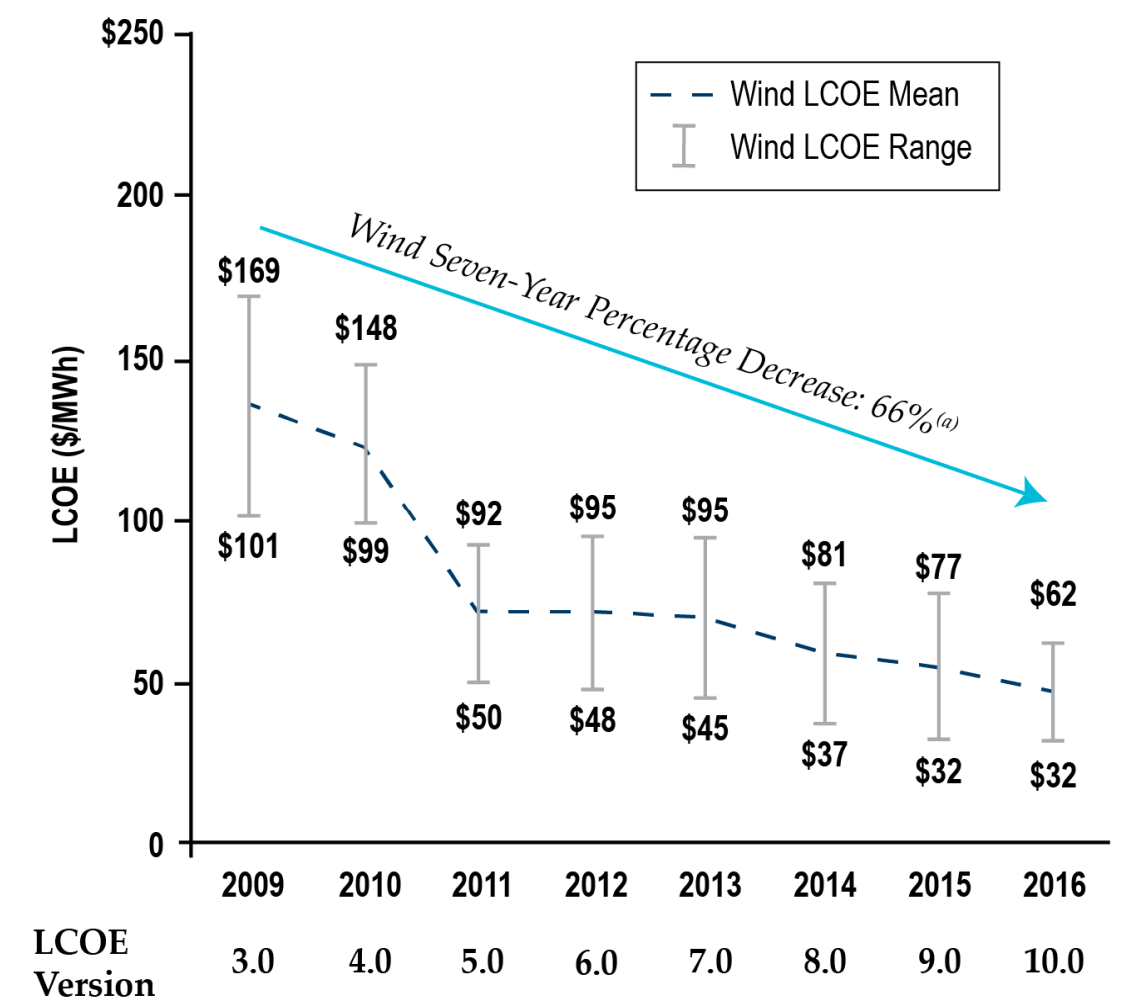

Figure 4. The LCOE of utility-scale wind energy for the period 2009-2016. Adapted from [4].

\subsubsection{Potential Environmental Effects and Types of Monitoring}

Potential environmental effects associated with wind energy development include bird and bat collisions (e.g., "collision" as used here refers to the potential for injury or death resulting from strikes with turbine blades, as well as from the pressure changes associated with moving blades, which may potentially injure or kill bats) with wind turbines and associated infrastructure; habitat loss and fragmentation caused by the addition of access roads, power distribution and transmission lines, and infrastructure to the landscape; displacement and other alterations of wildlife behaviors; and indirect effects such as benefits to populations of predators or invasive species [45,46].

\subsubsection{Factors Contributing to Easing Environmental Permitting}

Several factors have contributed to improving efficiencies and facilitating environmental permitting for terrestrial wind energy. These include permitting and regulatory solutions; partnerships formed among industry, agencies, and scientists and the collaborative research conducted by these partnerships; and the creation of guidance, protocols, and siting tools. 
Permitting and Regulatory Solutions

Mechanisms to improve efficiencies and facilitate environmental permitting of wind energy development that potentially apply to the MHK industry include programmatic NEPA review. To facilitate environmental permitting of wind energy development on public lands, the BLM, in cooperation with the DOE, prepared the Final Programmatic EIS on Wind Energy Development on BLM-Administered Lands in the Western United States [47]. This document evaluates potential impacts and identifies appropriate mitigation measures and BMPs, but does not evaluate site-specific issues; such effects must be evaluated at the project level. The BLM has approved several wind energy projects, some of which are operating. In contrast, the USFS has chosen not to pursue a programmatic NEPA review process, concluding it would be more efficient to examine individual sites as projects are proposed [48].

Partnerships and Collaborative Research

The partnerships and collaborative research in the terrestrial wind energy industry involve federal and state agencies, national laboratories, and collaborative/cooperative groups. Examples of such entities include the AWWI ${ }^{2}$, the National Wind Coordinating Collaborative (NWCC) ${ }^{3}$ Wildlife Workgroup, the Bat and Wind Energy Cooperative (BWEC) ${ }^{4}$, Working Together to Resolve Environmental Effects of Wind Energy, the DOE's Office of Energy Efficiency and Renewable Energy (EERE), the NREL, and the California Energy Commission (CEC). The partnerships function as interfaces among the wind energy industry, government agencies, academia, utility providers, and environmental organizations. They fund collaborative research to reduce the risks to wildlife from wind energy development, maintain online libraries of published and unpublished (but publicly available) documents on the environmental effects of wind energy, exchange data and information, and develop BMPs and mitigation measures for the responsible development of wind energy [35,49-51]. Collaborative research has led to technological advances that are expected to reduce environmental monitoring costs, improve data collection, and potentially reduce impacts on wildlife. Examples include the use of biotelemetry devices to detect large birds (e.g., raptors and cranes) so that appropriate measures can be taken to reduce the risk of collision with turbines [52], use of "smart curtailment" hardware and software systems to curtail turbine operation based on predictive models and real-time bat activity [53], and development of ultrasonic acoustic deterrents to reduce bat fatalities [54].

Guidance, Protocols, and Siting Tools

Guidance documents and protocols have been prepared to monitor, evaluate, and address wildlife conservation concerns and facilitate environmental permitting and compliance. Guidance documents developed by the USFWS are important tools being used to comply with the ESA, the MBTA, and the BGEPA. The U.S. Fish and Wildlife Service Land-Based Wind Energy Guidelines provide pre-and postconstruction tasks and include BMPs for construction, operation, retrofitting, repowering, and decommissioning [45]; the Eagle Conservation Plan Guidance uses a similar approach but is species-specific [55]. The Comprehensive Guide to Studying Wind Energy/Wildlife Interactions prepared for the NWCC details the available methods and metrics to study and evaluate interactions with wildlife [56], although the USFWS guidelines are likely more widely used. The Landscape Assessment Tool developed by the AWWI and The Nature Conservancy is a publicly available GIS-based mapping tool with over 1000 biological data layers to facilitate screening potential project sites [57]. The NREL maintains the Wind Prospector, a web-based GIS application to support resource assessment and data exploration associated with potential wind energy development.

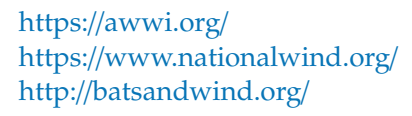




\subsubsection{MHK Industry Application}

Permitting pathways in the terrestrial wind energy have been made more efficient and effective through permitting and regulatory solutions; partnerships formed among industry, agencies, and scientists and the collaborative research conducted by these partnerships; and the development of guidance and tools. The programmatic EIS that was jointly prepared by the BLM and the DOE for wind energy projects on public lands has facilitated environmental permitting by evaluating potential effects and identifying appropriate mitigation and BMPs that can be used to prepare site-specific, tiered EAs. The NWWC's Wildlife Workgroup of volunteers from the public and private sectors, academia, and NGOs, collaborate to address wind-wildlife and wind-habitat interactions and develop the best practices for project siting and operation. Government agencies such as the DOE and the CEC have been supporting collaborative research projects to reduce the risks to wildlife from wind energy development. Resources available to assist the terrestrial wind energy industry include online searchable libraries (e.g., Tethys and the American Wind Wildlife Information Center), guidance documents and protocols, the Landscape Assessment Tool, and the Wind Prospector. The MHK industry can apply lessons from the terrestrial wind industry by engaging the DOE and the BOEM to conduct a programmatic NEPA review for MHK projects; identifying collaborative research opportunities with government funding; forming partnerships among regulatory agencies, industry professionals, and subject matter experts to address environmental effects and permitting; and developing publicly available tools to inform MHK projects.

\subsection{Solar Energy}

The solar energy industry in the U.S. has grown tremendously over the past 20 years. Much of the growth can be attributed to the combination of federal and state tax incentives, state-level mandates for increasing renewable generation (including solar-specific carve outs for some states), the lower cost of photovoltaic modules, and the market for distributed generation, which is unique compared to other renewable technologies such as wind and geothermal. The main types of solar energy generation technologies are photovoltaics (PV) and concentrating solar power (CSP) [58].

\subsubsection{Changes in Levelized Cost of Energy over Time}

Currently, the market for solar is dominated by PV, with utility-scale projects having a lower LCOE than distributed generation. The LCOE (unsubsidized) for utility-scale solar (with no storage) in 2016 ranged from $\$ 46$ to $\$ 61 / \mathrm{MWh}[4]$, with the variability dependent mainly on the solar resource available at that location. CSP has a higher LCOE than PV, ranging between $\$ 119$ and $\$ 182 / \mathrm{MWh}$ (unsubsidized) in 2016 [4]. The LCOE for rooftop residential PV was highest, ranging between $\$ 138$ and \$222/MWh.

The LCOE of solar declined by 85\% between 2009 and 2016 [4]. Much of the cost reduction in utility-scale PV has been realized thanks to the lower costs of crystalline silicon and the increased efficiencies and economies of scale by engineering, procurement, and construction (EPC) companies that develop large, utility-scale power plants. The PPA prices have declined over time and are likely also contributing to lowering the cost of utility-scale PV.

None of the studies referenced specify the environmental permitting and compliance costs associated with solar. A CEC report on the cost of new renewable and fossil fuel energy generation in California explicitly stated that the commission did not include the cost of land or permitting in its cost estimates for solar [59]. However, industry experts estimate that the typical cost of environmental permitting is less than $10 \%$ of the total costs of a project, with an extreme case as high as $16 \% .^{5}$

5 Interview with environmental consultant, 10 August 2017. All interviews were conducted in confidentiality, and the names of interviewees are withheld by mutual agreement. 


\subsubsection{Potential Environmental Effects and Types of Monitoring}

Potential environmental effects associated with solar energy development include habitat loss and fragmentation caused by the addition of access roads, power distribution and transmission lines, and infrastructure to the landscape; habitat disturbance; vehicle collisions with terrestrial animals or crushing of their burrows during construction; avian fatalities caused by collisions with PV panels; towers, or heliostats; and burning/singeing of birds that pass through a CSP $[60,61]$.

\subsubsection{Factors Contributing to Easing Environmental Permitting}

Several factors have contributed to improving and facilitating environmental permitting for solar energy projects. These include permitting and regulatory solutions; partnerships formed among industry, agencies, and scientists and the collaborative research conducted by these partnerships; and the formation of guidance, protocols, and siting tools.

Permitting and Regulatory Solutions

Development on Private Lands. Environmental considerations and the uncertainties surrounding the costs of environmental permitting and compliance make it more difficult for developers to construct on federal lands, so most solar development has occurred on private lands [58], specifically farmland that is converted for solar energy generation using site leases with a PPA. Many state and federal incentive programs, as well as PPA contracts, require tight timelines for project completion. Although private land solar developments undergo environmental review at the state level for their impacts on natural resources, the permitting pathways are easier to navigate-development objectives for improving the local tax base support greater certainty in permitting at the state and local level. Siting of solar energy developments is important: it can be much cheaper to develop solar on degraded agricultural lands and/or lands lacking threatened and endangered species.

Programmatic NEPA Review. In the western U.S., where the solar market is maturing and as undeveloped private land with access to the transmission and distribution grid becomes scarce, more utility-scale developers will start considering federal lands. To incentivize solar development on public lands and simplify the federal permitting process, the BLM developed the Final Programmatic EIS for Solar Energy Development in Six Southwestern States [33]. This document identifies 17 solar energy zones-in Arizona, California, Colorado, New Mexico, Nevada, and Utah-that are well suited for solar energy development and present the least potential for environmental impact, as well as zones that are to be excluded from solar development. The EIS also identifies variance areas that are outside the solar energy zones, but will be considered by the BLM for solar development. The identified zones are now available for development, provided the prescribed programmatic design features are implemented as part of the permitting process, with the intent of reducing the uncertainty around the time and costs incurred by the solar developer.

It is not yet clear whether the BLM effort to delineate areas that are off limits for development has successfully reduced environmental permitting and compliance costs. The BLM does not list pending permit applications on its website. Nevertheless, in the long term, the BLM program provides a good example of federal, state, and local collaboration to anticipate development, conduct baseline studies proactively, and potentially share the cost burden of environmental compliance with industry.

\section{Partnerships and Collaborative Research}

The partnerships and collaborative research in the solar energy industry involve federal, state, and local agencies, collaborative/cooperative groups, and academic partnerships. Examples of these entities include the Avian-Solar Collaborative Working Group, California Renewable Energy Policy Group (REPG), and the DOE's Solar Energy Technologies Office. The partnerships function as interfaces among the solar energy industry, government agencies, academia, and other stakeholders (e.g., public, non-governmental organizations). The Avian-Solar Collaborative Working Group of federal and 
state agency personnel addresses issues regarding the impacts of large-scale solar development on avian species, including avian attraction to solar energy structures, to help inform the permitting process. The REPG is composed of personnel from federal and state agencies responsible for permitting renewable energy and transmission projects, and conducts joint reviews to help reduce permitting times in California. The SunShot Initiative developed by the DOE's Solar Energy Technologies Office functions as a roadmap to reduce the LCOE of solar energy [62]. This program is intended to consolidate research efforts, fund technology improvements, and identify areas for cost-reductions, including environmental permitting and compliance costs. The SunShot Initiative has funded efforts to reduce these costs, such as developing software that simulates solar glare hazards from PV and CSP to help minimize impacts on birds, and conducting research on appropriate siting of solar projects on BLM lands.

Guidance, Protocols, and Siting Tools

On federal lands, programmatic NEPA review in the Western US has identified sites for solar development that minimize environmental impacts [33]. On private lands, a similar example includes "The Solar and the San Joaquin Valley Identification of Least-Conflict Lands Project", that was implemented to reduce land-use conflicts associated with solar development siting through stakeholder-led coordination that included federal, state, and local regulatory agencies and provided a basis for project- and programmatic-level permitting [63]. The EPA encourages solar development on current and formerly contaminated lands, landfills, and mine sites when development aligns with the community's vision for the site, and has developed the RE-Powering Initiative decision tree, a downloadable computer tool that guides interested parties through a process for screening sites for their suitability for solar installations [64].

\subsubsection{MHK Industry Application}

Permitting pathways in the solar energy industry have been made more efficient by permitting and regulatory solutions, as well as partnerships formed among industry professionals, regulatory agencies and subject matter experts to inform the permitting process and reduce permitting time frames. The BLM's PEIS for solar energy development aims to reduce the uncertainties associated with permitting costs and time frames by identifying 17 zones available for development and prescribing design features that are implemented as part of the permitting process. Collaborative efforts (e.g., the BLM program, Avian-Solar Collaborative Working Group, and REPG) to inform the permitting process include conducting studies (e.g., baseline characterization and environmental effect analyses), completing joint reviews of permit applications, and developing best practices. Additionally, the solar energy industry is developing technology to reduce the environmental effects of solar energy plants (e.g., avian mortality). The MHK industry can apply lessons from the solar energy industry by conducting programmatic NEPA reviews to enable tiering of site-specific EAs; forming partnerships among regulatory agencies, MHK developers, and subject matter experts to address permitting uncertainties; and developing technology to reduce the environmental effects of MHK projects.

\section{Lessons Learned}

Across the industries we reviewed, a relatively low proportion (i.e., $<10 \%$ ) of the LCOE or cost of development has been attributed to environmental permitting. However, the unpredictability of permitting costs remains an issue, and many projects likely exceed predicted costs. ${ }^{2}$ Reductions in the LCOE over time have been largely attributed to improvements in technology and not to lowering of permitting costs.

2 https://awwi.org/ 
We identified increased efficiencies and improvements in environmental permitting pathways that have been applied to offshore oil and gas development, offshore wind energy, subsea cables, terrestrial wind energy, and solar energy, all of which are applicable to MHK development and may be used to reduce environmental permitting and compliance costs for the emerging MHK industry. The following sections summarize the pathways identified to potentially reduce costs and improve efficiency and effectiveness of permitting and compliance.

\subsection{Use Existing Baseline Studies and Effects Analyses}

Leverage relevant existing knowledge about analogous structures, locations, organisms, effects, or mitigation to support permitting. Using known information, baseline studies, and analogous mitigation and monitoring techniques from the MRE industry and other marine industries (subsea cables and offshore oil and gas) can help to reduce the cost of environmental permitting and compliance. Existing effects analyses for analogous structures and activities from other marine industries should be used whenever applicable, such as those for subsea power and data cables, moorings and buoys, lighting on offshore structures, and vessel operations.

- Information on subsea cable installation can apply to the cable installation portion of MHK projects.

- Baseline regional studies on the at-sea distribution of marine organisms (e.g., marine mammals and birds) conducted for offshore wind energy can be used for MHK projects in the same region.

- Research has determined that there is likely little biological response to EMFs from power cables [16], and this information should be applied to all future MHK projects to reduce the need for EMF monitoring and costly mitigation.

- The State of the Science 2020 Report, OES-Environmental 2020 State of the Science Report: Environmental Effects of Marine Renewable Energy Development around the World, evaluates a variety of potential impacts from MRE projects, including MHK [17].

- There are far more offshore wind energy farms in Europe than in the U.S., so information on the potential environmental impacts at these farms should be leveraged, especially where there is precedent that impacts on analogous resources are likely minor or negligible [65].

- Data Transferability and Collection Consistency. An Annex IV workshop, held in June 2018 in Cherbourg, Normandy, France around the International Conference on Ocean Energy, examined ways to "transfer" data, information, and insight on environmental effects from early MRE projects to future projects, in order to leverage what was learned from early projects, reduce the high costs of environmental monitoring, and accelerate the permitting and licensing timeline for future projects. The workshop focused on identifying BMPs for data transfer and collection consistency, and built on previous workshops held with MRE regulators to understand their ability to use data from one project or an analogous industry to permit or license another MRE projects [66].

\subsection{Develop Permitting and Regulatory Solutions}

Scrutinize and consider the benefits offered by programmatic permits and government incentives, and consider approaches to improve programs. Given a lack of a cohesive U.S. renewable energy policy and very few permitted MHK developments in the U.S. thus far, there are no regions in the U.S. that more easily support MHK development at this time, and the various agencies are not integrated or aligned to facilitate the permitting process. We recommend engaging agencies from all regions and encouraging an efficient and agreed-upon approach to addressing uncertainty during permitting and compliance. Below we summarize the current status of permitting and regulatory solutions.

Programmatic documents (e.g., the BOEM's PEIS [1]) have limited abilities to reduce permitting costs because detailed project- and site-specific effect analyses are still required. A programmatic approach may be more effective when there are more proposed MHK projects within regions of the U.S. that would be covered under programmatic documents. In addition, in offshore wind, the BOEM 
has published guidance ${ }^{6}$ that encourages identifying draft designs, and then considering the envelope or range of potential impacts as a way to address the environmental review process more efficiently. This concept has also been applied in MHK permitting of test centers where there is limited information on the types of devices or technologies that could be tested in the future. Developing these concepts to assist in the early stages as the range of MHK technologies is broader may help clarify for the regulatory process what potential impacts may need to be evaluated. Applying these concepts for MHK may help inform potential impacts for individual projects moving forward, assuming the envelope approach applied is shared across projects.

Although there are regional or state initiatives or goals for renewable energy, a cohesive U.S. renewable energy policy has not been established. The enactment of a cohesive federal policy for MRE development would provide permitting and compliance guidance to regulatory agencies, facilitate more efficient and less costly permitting and compliance pathways, and support the development of, and effect assessment for, MHK technologies [42]. Regulatory agencies are not integrated or aligned for the permitting process in most energy industries, including MHK, which creates time-intensive coordination work for agency personnel, developers, and other stakeholders involved. ${ }^{7}$ There are also notable regional differences in the efficiency and ease of environmental permitting for other industries. For those with a long history of development, such as oil and gas development in the Gulf of Mexico and terrestrial wind energy in most of the U.S., the process is easily facilitated by the various agencies involved. ${ }^{7}$ In novel locations or industries (e.g., oil and gas in Alaska, or solar energy in the western U.S.), and particularly in areas where a project may be met by litigation or resistance from stakeholders, regulatory agencies tend to exert greater scrutiny during the permitting process, making it more costly and time-consuming. Proactively working with the public and stakeholders to address their concerns, evaluate environmental issues, and disseminate information for individual projects is also crucial to facilitating efficient environmental review and permitting.

\subsection{Form Partnerships to Conduct Collaborative Research}

Build and exchange knowledge proactively for screening risk. Partnerships among industry, scientists, regulatory agencies, and environmental and other non-governmental organizations can be formed to collaborate on and fund research on priority topics, assess impacts, and set industry standards and BMPs. These types of partnerships have been formed for most of the other industries and have been effective, particularly for terrestrial wind energy. Engaging and working with the different regulatory agencies on existing projects, technologies, and current research can help inform their assessments and ease the permitting process for proposed and future projects. However, this pathway will likely require substantial funding from government sources (e.g., the DOE and the BOEM) in the near future. As the industry matures into commercialization, this pathway can evolve to be funded through other sources. Examples of approaches to build and exchange knowledge are conducting regional environmental characterizations to collect broad-scale data (e.g., physical, biological, and cultural) to reduce costs and needs for baseline monitoring; funding targeted research on environmental baseline conditions and monitoring technologies that can be applied to multiple projects in a region; and funding the development of predictive models for risk assessment.

\subsection{Develop and Implement Guidance, Protocols, and Siting Tools}

Document, use, and share the best ways to minimize effects and other issues. Guidance documents, protocols, and siting tools can be created and implemented to evaluate, monitor, and address potential

6 https://www.boem.gov/Draft-Design-Envelope-Guidance/

7 Email communication with environmental consultant, 16 January 2018. All interviews were conducted in confidentiality, and the names of interviewees are withheld by mutual agreement.

7 Email communication with environmental consultant, 16 January 2018. All interviews were conducted in confidentiality, and the names of interviewees are withheld by mutual agreement. 
issues and facilitate environmental permitting and compliance. These types of documents exist for subsea cable installation, offshore renewable energy (which includes MHK development), and terrestrial wind energy; good examples from the offshore wind energy industry are Developing Environmental Protocols and Modeling Tools to Support Ocean Renewable Energy and Stewardship [38] and West Coast Environmental Protocols Framework: Baseline and Monitoring Studies [29]. Implementing a collaborative approach for least-conflict siting analysis at the regional scale may provide some time and cost savings for future MHK projects in the U.S., and could form the basis for project- and programmatic-level permitting, as has been done for solar energy projects in the Central Valley of California [63].

\subsection{Continue to Hone Technology and Installation}

Seek out winning standards and pursue efficiencies. Looking at changes over time in the LCOE and development costs for other industries, it is reasonable to assume that cost savings will arise through technological advancements and increased efficiencies, particularly should MHK devices or components such as moorings, anchors, lighting, become more standardized. MHK devices currently are in the testing stage, and it is expected that at some point certain design commonalities will start to emerge. Once particular design types become more standardized, cost savings will be realized through more efficient production and standardized installation procedures; this occurred for the offshore wind, terrestrial wind, and solar energy industries. In addition, potential environmental effects can be more efficiently evaluated when there is standardization of project features such as anchoring, mooring, and lighting, rather than a large and variable field of designs and configurations.

Ultimately, the advancement of the MHK industry in the U.S. will require a concerted collaborative effort between developers, regulatory agencies, and stakeholders to determine the optimal approaches to streamline the environmental permitting and compliance processes. This effort will lower costs, increase efficiencies, and decrease uncertainties for developing MHK projects in the U.S. The emerging MHK industry in the U.S. should incorporate the strategies and actions developed by other industries and apply them at both the national and regional levels.

Author Contributions: The article conceptualization was developed by the entire team; the methodology development and analysis was conducted by S.K., C.J. and G.K.; writing-original draft preparation, S.K. and C.J.; writing-review and editing, G.K., J.R., and A.W.; supervision, A.W. and Z.B.; project administration, Z.B.; funding acquisition was conducted by the entire team. All authors have read and agreed to the published version of the manuscript.

Funding: This research was funded by the U.S. Department of Energy, Office of Energy Efficiency and Renewable Energy, Water Power Program.

Acknowledgments: This study would not have been possible without our Department of Energy program manager Samantha Eaves and technical support staff. Thank you to all of the supporting staff at H. T. Harvey \& Associates; Integral Consulting, Inc.; Kearns \& West; and Sandia National Laboratories for providing their expertise and manuscript review. The views expressed in the article do not necessarily represent the views of the U.S. Department of Energy. Sandia National Laboratories is a multimission laboratory managed and operated by National Technology \& Engineering Solutions of Sandia, LLC, a wholly owned subsidiary of Honeywell International Inc., for the U.S. Department of Energy's National Nuclear Security Administration under contract DE-NA0003525. This paper describes objective technical results and analysis. Any subjective views or opinions that might be expressed in the paper do not necessarily represent the views of the U.S. Department of Energy or the United States Government.

Conflicts of Interest: The authors declare no conflict of interest.

\section{References}

1. Copping, A.E.; Freeman, M.C.; Overhus, D.M. Risk Retirement for Environmental Effects of Marine Renewable Energy; PNNL-29996; Pacific Northwest National Lab. (PNNL): Richland, WA, USA, 2020.

2. O'Neil, R.; Staines, G.; Freeman, M. Marine Hydrokinetics Regulatory Processes Literature Review; Report for USA Department of Energy; Pacific Northwest National Laboratory: Washington, DC, USA, 2019. 
3. Minerals Management Service. Programmatic Environmental Impact Statement for Alternative Energy Development and Production and Alternate Use of Facilities on the Outer Continental Shelf; Minerals Management Service: Washington, DC, USA, 2007.

4. Lazard. Lazard's Levelized Cost of Energy Analysis-Version 10.0. Available online: https://www.lazard. com/perspective/levelized-cost-of-energy-analysis-100/ (accessed on 22 December 2017).

5. U.S. Bureau of Ocean Energy Management. 2019-2024 National Outer Continental Shelf Oil and Gas Leasing Draft Proposed Program; Bureau of Ocean Energy Management: Washington, DC, USA, 2018.

6. Agency for the Cooperation of Energy Regulators. Report on unit investment cost indicators and corresponding reference values for electricity and gas infrastructure. In Electricity Infrastructure; Version 1.1; Agency for the Cooperation of Energy Regulators: Ljubljana, Slovenia, 2015.

7. Regional Group North Sea for the NSCOGI. Offshore Transmission Technology; European Network of Transmission System Operators for Electricity: Brussels, Belgium, 2011.

8. Taormina, B.; Bald, J.; Want, A.; Thouzeau, G.; Lejart, M.; Desroy, N.; Carlier, A. A review of potential impacts of submarine power cables on the marine environment: Knowledge gaps, recommendations, and future directions. Renew. Sustain. Energy Rev. 2018, 96, 380-391. [CrossRef]

9. Carter, L.; Burnett, D.; Davenport, T. The relationship between submarine cables and the marine environment. In Submarine Cables: The Handbook of Law and Policy; Martinus Nijhoff Publishers: Leiden, The Netherlands, 2014.

10. Carter, L.; Burnett, D.; Drew, S.; Marle, G.; Hagadorn, L.; Bartlett-McNeil, D.; Irvine, N. Submarine Cables and the Oceans-Connecting the World; UNEP-WCMC Biodiversity: Cambridge, UK, 2009.

11. TEC. Final Programmatic Environmental Assessment for National Science Foundation-Funded Ocean Observatories Initiative (OOI); National Science Foundation, Division of Ocean Sciences: Arlington, VA, USA, 2008.

12. Normandeau; Exponent; Tricas, T.; Gill, A. Effects of EMFs from Undersea Power Cables on Elasmobranchs and Other Marine Species; U.S. Department of the Interior, Bureau of Ocean Energy Management, Regulation, and Enforcement, Pacific OCS Region: Camarillo, CA, USA, 2011.

13. Love, M.S.; Nishimoto, M.M.; Clark, S.; Scarborough Bull, A. Identical response of caged rock crabs (Genera Metacarcinus and Cancer) to energized and unenergized undersea power cables in southern California, USA. Bull. South. Calif. Acad. Sci. 2015, 114, 33-41.

14. Love, M.S.; Nishimoto, M.M.; Clark, S.; Bull, A.S. Renewable Energy In Situ Power Cable Observation; U.S. Department of the Interior, Bureau of Ocean Energy Management, Pacific OCS Region: Camarillo, CA, USA, 2016.

15. Gill, A. Effects of EMF on marine animals from electrical cables and marine renewable energy devices. In Annex IV 2016 State of the Science Report: Environmental Effects of Marine Renewable Energy Development Around the World; Pacific Northwest National Laboratory: Richland, WA, USA, 2016.

16. U.S. Bureau of Ocean Energy Management. Applied Science for Informed Decisions on Ocean Energy; Environmental Studies-Electromagnetic Fields (EMF); Bureau of Ocean Energy Management: Washington, DC, USA, 2016. Available online: https://www.boem.gov/sites/default/files/boem-newsroom/Library/ScienceNote/Science-Notes.pdf (accessed on 22 December 2017).

17. Copping, A.E.; Hemery, L.G. (Eds.) Environmental 2020 State of the Science Report: Environmental Effects of Marine Renewable Energy Development Around the World; Report for Ocean Energy Systems; Ocean Energy Systems-Environmental; Pacific Northwest National Lab. (PNNL): Richland, WA, USA, 2020.

18. Copping, A.; Sather, N.; Hanna, L.; Whiting, J.; Zydlewski, G.; Staines, G.; Gill, A.; Hutchison, I.; O’Hagan, A.; Simas, T.; et al. Annex IV 2016 State of the Science Report: Environmental Effects of Marine Renewable Energy Development Around the World; Ocean Energy Systems-Annex IV; Pacific Northwest National Lab. (PNNL): Richland, WA, USA, 2016.

19. Kavet, R.; Wyman, M.T.; Klimley, A.P.; Vergara, X. Assessment of Potential Impact of Electromagnetic Fields from Undersea Cable on Migratory Fish Behavior, Period Covering: January 2014-June 2016; Electric Power Research Inst. (EPRI): Palo Alto, CA, USA, 2016.

20. Woodruff, D.L.; Cullinan, V.I.; Copping, A.E.; Marshall, K.E. Effects of Electromagnetic Fields on Fish and Invertebrates-Task 2.1.3: Effects on Aquatic Organisms Fiscal Year 2012 Progress Report-Environmental Effects of Marine and Hydrokinetic Energy; Pacific Northwest National Lab (PNNL): Richland, WA, USA, 2013.

21. OSPAR Commission. Guidelines on Best Environmental Practice (BEP) in Cable Laying and Operating; OSPAR Commission: London, UK, 2012. 
22. National Oceanic and Atmospheric Administration, Office of National Marine Sanctuaries. Final Policy and Permit Guidance for Submarine Cable Projects; National Oceanic and Atmospheric Administration: Silver Spring, MD, USA, 2011.

23. U.S. Navy. Naval Facilities Engineering Command. In Naval Seafloor Cable Protection Office GIS-GIS Data Library and Mapping Capabilities; U.S. Navy Cable Protection Office: Washington, DC, USA, 2017; Available online: https://www.navfac.navy.mil/products_and_services/ci/products_and_ services/naval_ocean_facilities_program/sea_floor_cable_protection_nscpo/nscpo_maps.html (accessed on 22 December 2017).

24. Crabtree, C.J.; Zappala, D.; Hogg, S.I. Wind energy: UK experiences and offshore operational challenges. J. Power Energy 2015, 229, 727-746. [CrossRef]

25. Musial, W.; Beiter, P.; Schwabe, P.; Tian, T.; Stehly, T.; Spitsen, P. 2016 Offshore Wind Technologies Market. Report; US Department of Energy, Office of Energy Efficiency and Renewable Energy: Washington, DC, USA, 2016.

26. Wiser, R.; Jenni, K.; Seel, J.; Baker, E.; Hand, M.; Lantz, E.; Smith, A. Forecasting Wind Energy Costs and Cost Drivers: The Views of the World's Leading Experts; IEA Wind Task 26; Electricity Markets \& Policy: Berkeley, CA, USA, 2016.

27. National Marine Fisheries Service. Endangered Species Act (ESA) Section 7 Consultation for Deepwater Wind; National Marine Fisheries Service: Silver Spring, MD, USA, 2015.

28. ICES. Working Group on Marine Benthal and Renewable Energy Developments (WGMBRED); International Council for the Exploration of the Sea (ICES): Copenhagen, Denmark, 2019.

29. Klure, J.; Hampton, T.; McMurray, G.; Boehlert, G.; Henkel, S.; Copping, A.; Kramer, S.; Chwaszczewski, R.; Fresh, K. West. Coast. Environmental Protocols Framework: Baseline and Monitoring Studies; Pacific Energy Ventures: Portland, OR, USA, 2012.

30. U.S. Department of Energy; U.S. Department of the Interior. National Offshore Wind Strategy: Facilitating the Development of the Offshore Wind Industry in the United States; National Renewable Energy Lab. (NREL): Golden, CO, USA, 2016.

31. Environmental Law Institute. A Guide to State Management of Offshore Wind Energy in the Mid-Atlantic Region; Mid-Atlantic Regional Council on the Ocean: Williamsburg, VA, USA, 2013.

32. Normandeau Associates, Inc. High-Resolution Aerial Imaging Surveys of Marine Birds, Mammals, and Turtles on the US Atlantic Outer Continental Shelf-Utility Assessment, Methodology Recommendations, and Implementation Tools; U.S. Bureau of Ocean Energy Management: Herndon, VA, USA, 2012.

33. Normandeau Associates, Inc. Acoustic Monitoring of Temporal and Spatial Abundance of Birds Near Outer Continental Shelf Structures: Synthesis Report; U.S. Bureau of Ocean Energy Management: Gainesville, FL, USA, 2014.

34. Suryan, R.; Albertani, R.; Polagye, B. Synchronized Sensor Array for Remote Monitoring of Avian and Bat Interactions with Offshore Renewable Energy Facilities; Oregon State University: Corvallis, OR, USA, 2016.

35. Tethys Environmental Effects of Wind and Marine Renewable Energy. Available online: https://tethys.pnnl. gov/ (accessed on 22 December 2017).

36. U.S. Bureau of Ocean Energy Management. State Activities. Available online: https://www.boem.gov/ Renewable-Energy-State-Activities (accessed on 22 December 2017).

37. U.S. Bureau of Ocean Energy Management; California Public Utilities Commission; California Energy Commission. California Offshore Wind Energy Gateway. Available online: https://caoffshorewind.databasin. org/ (accessed on 22 December 2017).

38. McCann, J. Developing Environmental Protocols and Modeling Tools to Support Ocean Renewable Energy and Stewardship; U.S. Department of the Interior, Bureau of Ocean Energy Management, Office of Renewable Energy Programs: Herndon, VA, USA, 2012.

39. U.S. Bureau of Safety and Environmental Enforcement. Offshore Wind Submarine Cable Spacing Guidance; U.S. Department of the Interior, Bureau of Ocean Energy Management, Office of Renewable Energy Programs: Herndon, VA, USA, 2014.

40. Sharples, M. Offshore Electrical Cable Burial for Wind Farms: State of the Art, Standards and Guidance E Acceptable Burial Depths, Separation Distances and Sand Wave Effect; U.S. Bureau of Ocean Energy Management, Regulation \& Enforcement: Washington, DC, USA, 2011. 
41. Orr, T.; Herz, S.; Oakley, D. Evaluation of Lighting Schemes for Offshore Wind Facilities and Impacts to Local Environments; U.S. Bureau of Ocean Energy Management, Office of Renewable Energy Programs: Herndon, VA, USA, 2013.

42. Baring-Gould, E.I.; Christol, C.; LiVechi, A.; Kramer, S.; West, A. A Review of the Environmental Impacts for Marine and Hydrokinetic Projects to Inform Regulatory Permitting: Summary Findings from the 2015 Workshop on Marine and Hydrokinetic Technologies, Washington, DC; National Renewable Energy Laboratory: Golden, CO, USA, 2016.

43. Allison, T.D. Eagles and Wind Energy: Identifying Research Priorities; American Wind Wildlife Institute: Washington, DC, USA, 2012.

44. Lantz, E.; Wiser, R.; Hand, M. IEA Wind Task 26: The Past and Future Cost of Wind Energy; Work Package 2; National Renewable Energy Laboratory: Golden, CO, USA, 2012.

45. U.S. Fish and Wildlife Service. Land-Based Wind Energy Guidelines; U.S. Fish and Wildlife Service: Washington, DC, USA, 2012.

46. American Wind Wildlife Institute. Wind Turbine Interactions with Wildlife and Their Habitats: A Summary of Research Results and Priority Questions; American Wind Wildlife Institute: Washington, DC, USA, 2016.

47. U.S. Bureau of Land Management; U.S. Department of Energy. Final Programmatic Environmental Impact Statement (PEIS) for Solar Energy Development in Six Southwestern States; U.S. Department of Energy: Washington, DC, USA, 2012.

48. U.S. Forest Service. Final Directives for Forest Service Wind Energy Special Use Authorizations, Forest Service Manual 2720, Forest Service Handbooks 2609.13 and 2709.11; U.S. Forest Service: Washington, DC, USA, 2011.

49. National Renewable Energy Laboratory Wind-Wildlife Impacts Literature Database (WILD). Available online: https://wild.nrel.gov (accessed on 22 December 2017).

50. Bats and Wind Energy Cooperative Products Page. Available online: http://www.batsandwind.org/index. php/products-2 (accessed on 22 December 2017).

51. American Wind Wildlife Institute Documents Library. Available online: https://awwic.nacse.org/library.php (accessed on 22 December 2017).

52. Sheppard, J.K.; McGann, A.; Lanzone, M.; Swaisgood, R.R. An autonomous GPS geofence alert system to curtail avian fatalities at wind farms. Anim. Biotelemetry 2015, 3, 43. [CrossRef]

53. Normandeau Associates, Inc. Bat Detection and Shutdown System for Utility-Scale Wind Turbines; Electric Power Research Institute: Palo Alto, CA, USA, 2017.

54. Arnett, E.B.; Hein, C.D.; Schirmacher, M.R.; Huso, M.M.P.; Szewczak, J.M. Evaluating the effectiveness of an ultrasonic acoustic deterrent for reducing bat fatalities at wind turbines. PLOS ONE 2013, 8, e65794. [CrossRef]

55. U.S. Fish and Wildlife Service Eagle Conservation Plan Guidance. Module 1-Land-Based Wind Energy. Version 2; Division of Migratory Bird Management. 2013. Available online: https://www.fws.gov/ migratorybirds/pdf/management/eagleconservationplanguidance.pdf (accessed on 22 December 2017).

56. Strickland, M.D.; Arnett, E.B.; Erickson, W.P.; Johnson, D.H.; Johnson, G.D.; Morrison, M.L.; Shaffer, J.A.; Warren-Hicks, W. Comprehensive Guide to Studying Wind Energy/Wildlife Interactions; National Wind Coordinating Collaborative: Washington, DC, USA, 2011.

57. American Wind Wildlife Institute. American Wind Wildlife Information Center. Available online: https: //awwi.org/resources/tools/ (accessed on 22 December 2017).

58. Hernandez, R.R.; Hoffacker, M.K.; Field, C.B. Land-use efficiency of big solar. Environ. Sci. Technol. 2014, 48, 1315-1323. [CrossRef] [PubMed]

59. Rhyne, I.; Klein, J. Estimated Cost of New Renewable and Fossil Generation in California; California Energy Commission: Sacramento, CA, USA, 2015.

60. Hernandez, R.R.; Easter, S.B.; Murphy-Mariscal, M.L.; Masestre, F.T.; Tavassoli, M.; Allen, E.B.; Barrows, C.W.; Belnap, J.; Ochoa-Hueso, R.; Ravi, S.; et al. Environmental impacts of utility-scale solar energy. Renew. Sustain. Energy Rev. 2014, 29, 766-779. [CrossRef]

61. Ho, C.K. Review of Avian Mortality Studies at Concentrating Solar Power Plants. In Proceedings of the AIP Conference Proceedings 1734, 070017, Cape Town, South Africa, 13-16 October 2015; AIP Publishing: Cape Town, South Africa, 2016; Volume 1734. 
62. Walston, L.J.; Rollins, K.E.; LaGory, K.E.; Smith, K.P.; Meyers, S.A. A preliminary assessment of avian mortality at utility-scale solar energy facilities in the United States. Renew. Energy 2016, 92, 405-414. [CrossRef]

63. U.S. Bureau of Land Management. Desert Renewable Energy Conservation Plan, Proposed Land Use Plan. Amendment, and Final Environmental Impact Statement; U.S. Bureau of Land Management, U.S. Fish and Wildlife Service, California Energy Commission, and California Department of Fish and Wildlife: Washington, DC, USA, 2015. Available online: https://drecp.databasin.org/ (accessed on 22 December 2017).

64. Federal Permitting Improvement Steering Council Recommended Best Practices for Environmental Reviews and Authorizations for Infrastructure Projects. 2017. Available online: https://www.permits.performance.gov/ sites/permits.dot.gov/files/2019-10/FPISC\%20Best\%20Practices-\%20FINAL\%2001182017\%283\%29_0.pdf (accessed on 22 December 2017).

65. U.S. Department of Energy. SunShot Vision Study; U.S. Department of Energy: Washington, DC, USA, 2012.

66. Pearce, D.; Strittholt, J.; Watt, T.; Elkind, E.N. A Path Forward: Identifying Least-Conflict Solar Photovoltaic Development in California's San Joaquin Valley; University of California, Berkeley Law: Berkeley, CA, USA, 2016.

(C) 2020 by the authors. Licensee MDPI, Basel, Switzerland. This article is an open access article distributed under the terms and conditions of the Creative Commons Attribution (CC BY) license (http://creativecommons.org/licenses/by/4.0/). 